\title{
EDUCAÇÃO DE TEMPO INTEGRAL NO BRASIL, PASSOS E DESCOMPASSOS: DE RUY BARBOSA E ANÍSIO TEIXEIRA AOS DIAS ATUAIS
}

\author{
EDUCACIÓN DE TIEMPO INTEGRAL EN BRASIL, PASOS Y \\ DESCOMPASOS: DE RUY BARBOSA Y ANÍSIO TEIXEIRA A LOS DÍAS \\ ACTUALES
}

\begin{abstract}
FULL TIME EDUCATION IN BRAZIL, STEPS AND MISSTEPS: FROM RUY BARBOSA AND ANÍSIO TEIXEIRA TO CURRENT DAYS
\end{abstract}

\author{
Aniele Elis SCHEUERMANN ${ }^{1}$ \\ Hildegard Susana $\mathrm{JUNG}^{2}$ \\ Silvia Regina CANAN ${ }^{3}$
}

RESUMO: O presente artigo, de cunho bibliográfico e documental, objetiva refletir acerca das tentativas de implantação da Educação de Tempo Integral no Brasil. Para tanto, faz um resgate da reforma curricular proposta por Ruy Barbosa em 1879 que, mesmo não aprovada, tornou-se referência. Traz ainda a experiência de ensino integral de Anísio Teixeira com as Escolas Parque em Brasília, em 1960, narrando seu declínio dois anos mais tarde, devido a questões ideológicas e, principalmente, econômicas. Chegando aos dias atuais, apresenta a meta 6 do Plano Nacional de Educação (20142024), que prevê a Educação de Tempo Integral em pelo menos $50 \%$ das escolas e $25 \%$ dos alunos da educação básica, tendo como principal estratégia o programa Mais Educação. Entretanto, mais uma vez as metas e estratégias encontram-se ameaçadas pelos cortes econômicos e política da descontinuidade, com a redução dos recursos. É mister, portanto, estabelecer mecanismos de resistência que possibilitem a efetivação das metas já traçadas e dos programas instituídos, bem como esforços de todas as esferas envolvidas, de maneira a impedir que o retrocesso, o descaso, 0 desconhecimento, e a falta de prioridade da educação nas políticas públicas continuem com este ciclo vicioso.

PALAVRAS-CHAVE: Educação de Tempo Integral. Descontinuidade das Políticas Públicas. Mais Educação. Anísio Teixeira. Ruy Barbosa.

RESUMEN: El presente artículo, de cuño bibliográfico y documental, objetiva a reflexionar acerca de los intentos de implantación de la Educación de Tiempo Integral en Brasil. Para ello, hace un rescate de la reforma curricular propuesta por Ruy Barbosa en 1879 que, si bien no aprobada, se hizo referencia. Trae asimismo la experiencia de enseñanza integral de Anísio Teixeira con las Escuelas Parque en Brasília, en 1960, narrando su declinación dos años más tarde, debido a cuestiones ideológicas y, principalmente, económicas. Llegando a los días actuales, presenta la

\footnotetext{
${ }^{1}$ Mestranda em Educação URI - Câmpus de Frederico Westphalen RS. E-mail: aniele@ uri.edu.br

${ }^{2}$ Doutoranda em Educação, Unilasalle. Mestre em Educação, URI. E-mail: hildegardsjung@gmail.com

${ }^{3}$ Pedagoga, Doutora em Educação. Docente do PPG Educação URI - Câmpus de Frederico Westphalen RS. E-mail: silvia@uri.edu.br
} 
meta 6 del Plan Nacional de Educación (2014-2024), que prevé la Educación de Tiempo Integral en por lo menos el 50\% de las escuelas y el $25 \%$ de los alumnos de la educación básica brasileña, teniendo como principal estrategia el programa Mais Educação. Sin embargo, una vez más las metas y estrategias se encuentran amenazadas por los cortes económicos y la política de no continuidad, con la reducción de los recursos. Es menester, por tanto, establecer mecanismos de resistencia que posibiliten la efectuación de las metas ya trazadas y de los programas instituidos, así como esfuerzos de todas las esferas involucradas, de manera a impedir que el retroceso, el descaso, el desconocimiento, y la falta de prioridad de la educación en las políticas públicas continúen con este ciclo vicioso.

PALAVRAS CLAVE: Educación de Tiempo Integral. No continuidad de las Políticas Públicas. Mais Educação. Anísio Teixeira. Ruy Barbosa.

ABSTRACT: This article, of bibliographical and documental nature, aims to reflect on the attempts to implement Full-time Education in Brazil. Therefore, rescues the curriculum reform proposed by Ruy Barbosa in 1879, which, although not approved, became reference. It also brings the full teaching experience of Anisio Teixeira with the Parque Schools in Brasília, in 1960, chronicling its decline two years later due to ideological and especially economic issues. Coming to present days, introduces the goal 6 of the National Education Plan (2014-2024), which envisions Full-time Education in at least $50 \%$ of the schools and $25 \%$ of basic education students, having as main strategy the program "Mais Educação". However, once again the goals and strategies are threatened by economic cuts and policy discontinuity with the reduction of resources. It is therefore necessary to establish resistance mechanisms that enable the realization of the goals already outlined and established programs, as well as efforts of all involved spheres, in order to prevent that setbacks, negligence, unawareness and the lack of priority of education in public policies continue this vicious cycle.

KEYWORDS: Full-time Education. Discontinuity o Public Policies. "Mais Educação". Anísio Teixeira. Ruy Barbosa.

\section{Palavras iniciais}

A educação brasileira vem passando por constantes mudanças que visam a busca da qualidade, atendendo às exigências impostas por mecanismos internacionais, e procurando a abrangência nos diversos locais do país, atendendo a população de diferentes classes econômicas. A criação de políticas públicas que atendam a esses propósitos se torna cada vez mais imprescindível para fomentar a necessidade de melhorias no setor educacional, contudo, caminha a passos lentos sua implementação e implantação. A partir dessa análise, buscamos neste texto relatar as tentativas de instaurar em nosso país a Educação de Tempo Integral. 
Como metodologia, a investigação, de natureza qualitativa, utiliza a pesquisa bibliográfica e a consulta a documentos legais de domínio público. Mesmo não sendo nosso objetivo deter-nos na descrição das questões metodológicas, cumpre apenas que façamos o alinhamento filosófico e epistemológico da pesquisa, uma vez que a mesma busca entender o contexto histórico dos acontecimentos, garimpando, refletindo crítica e autocriticamente, mas entendendo também que o mundo se apresenta em sua 'pseudoconcreticidade' (KOSIK, 1976).

Dito isso, num primeiro momento, realizamos uma incursão às primeiras ideias sobre educação integral no Brasil, propostas na reforma que pretendia o Ruy Barbosa no Brasil Império, as disciplinas e conteúdos por ele propostos, bem como algumas centelhas do contexto histórico e ideológico que circundava a educação na época. Seguindo, passamos à descrição das principais ideias de Anísio Teixeira e seu mestre John Dewey no que diz respeito aos objetivos da educação na formação dos indivíduos, onde encontramos curiosas aproximações com o próprio Ruy Barbosa e outros, além de questionamentos sobre a maneira de ensinar. Em seguida, analisamos os objetivos da Educação de Tempo Integral, realizando uma pequena distinção entre educação integral e tempo integral, buscando nos autores de referência nossa fundamentação. Por último, trazemos a experiência de Educação de Tempo Integral de Anísio Teixeira em Brasília com as Escolas Parque e o atual Programa Mais Educação, considerado a principal estratégia para a implementação da Educação em Tempo Integral em pelo menos 50\% das escolas até 2024, conforme prevê o Plano Nacional de Educação (PNE) 2014-2024.

Para compreender este processo, por intermédio desta pesquisa, buscamos refletir sobre algumas questões que consideramos essenciais: A constituição do currículo escolar passa também por uma questão ideológica? Como as ideias de Ruy Barbosa e Anísio Teixeira se relacionam à criação de políticas públicas que buscam a qualidade da educação brasileira? O que é o programa Mais Educação e de que maneira o governo o avalia como importante para uma futura implantação da Educação de Tempo Integral? Por que não conseguimos dar continuidade às políticas públicas para implantação da Educação de Tempo Integral? O que podemos fazer com relação a isso?

\section{A construção do currículo no Brasil}


De acordo com Ferreira (2010, p. 214), o significado da palavra currículo tem sentido, entre outras, de “3. Descrição do conjunto de conteúdos ou matérias de um curso escolar ou universitário"4. Segundo a professora Solange Aparecida Zotti, do Grupo de Estudos e Pesquisas "História, Sociedade e Educação no Brasil", da Faculdade de Educação da UNICAMP, do ponto de vista etimológico, o termo currículo deriva da palavra latina Scurrere, correr. Assim, está relacionada à carreira, a um percurso que precisa ser andado. Zotti (2006), no verbete elaborado para o glossário da História da Educação Brasileira, explica que na área pedagógica o termo pode designar, além do plano estruturado de estudos, o tempo de cada matriz do currículo. Desta forma, podemos dizer que a educação integral é também um tipo de currículo, ou seja, o currículo integral.

A discussão sobre os conteúdos que deveriam compor o Currículo da escola popular acentuou-se na segunda metade de século XIX e, de acordo com Souza (2000, p. 9), esta temática já trazia consigo a ideia de universalização. Ainda assim, continua a autora, "diferentes interesses políticos ideológicos, religiosos, sociais, econômicos e culturais" tencionavam as negociações. Internacionalmente, circulava a ideia de que a escola poderia gerar progresso, mudança social e modernização, e os congressos, livros e artigos disseminavam estes modelos. Neste contexto de final de século XIX, como explica Petitat (1994), a maioria dos países, principalmente os mais desenvolvidos e aqueles em desenvolvimento, massificavam a escolarização, com aspectos em comum: a obrigatoriedade, a educação como responsabilidade do Estado, "a secularização do ensino e a secularização da moral, a nação e a pátria como princípios norteadores da cultura escolar, a educação popular concebida como um projeto de integração ideológica e política" (SOUZA, 2000, p. 11), e uma homogeneidade nos currículos.

No Brasil, a reforma do ensino foi apresentada por Ruy Barbosa ${ }^{5}$ (1849 - 1923) na época em que era Deputado Geral e relator da Comissão de Instrução Pública ao final dos anos de 1800. Rui Barbosa defendia uma "escola primária obrigatória e laica com

\footnotetext{
${ }^{4}$ O Dicionário Interativo da Educação Brasileira (http://www.educabrasil.com.br/eb/dic/dicionario.asp) define currículo como o "Conjunto de disciplinas sobre um determinado curso ou programa de ensino ou a trajetória de um indivíduo para o seu aperfeiçoamento profissional".

${ }^{5}$ A longa carreira política de Ruy Barbosa de Oliveira iniciou-se em 1878 e foi até 1921 (SOUZA, 2000). "A história da Educação Brasileira relata que os alentados Pareceres sobre a Reforma do Ensino Primário, Secundário e Superior, de autoria de Ruy Barbosa, foram elaborados na vigência do Decreto n. 7.247, de 19 de abril de 1879, expedido pelo ministro do Império, o Conselheiro professor Carlos Leôncio de Carvalho, conforme podemos constatar no volume X, tomo IV, da edição de 1947, da "Reforma do Ensino Primário e várias instituições complementares da instrução pública" (BONATO, COELHO e MENEZES, 2011, p. 276).
} 
oito anos de duração" (SOUZA, 2000, p. 12). Após analisar a situação educacional do país, o jurista encaminhou substitutivo ao Decreto n. 7.247, de 19 de abril de 1879, de Leôncio de Carvalho, propondo reformas ao ensino primário, secundário e superior. Além disso, defendia o desenvolvimento de um sistema nacional de educação. Ainda que a reforma proposta por Ruy Barbosa não tenha sido aceita, optamos por apresentá-la de forma bastante detalhada, posto que tornou-se uma referência na educação do país e inspiração para desenvolvimento de políticas educacionais futuras. A tabela 01 apresenta as disciplinas básicas pensadas pelo legislador para o sistema educacional brasileiro e os principais conteúdos/métodos para desenvolvê-las. Além disso, ele selecionou os "conteúdos que, na sua opinião, melhor atendiam às finalidades de modernização do país e de formação das camadas populares; conteúdos que correspondessem ao princípio da educação integral e fossem atestados pelos países mais civilizados" (SOUZA, 2000, p. 16).

TABELA 01: A reforma curricular apresentada por Ruy Barbosa

\begin{tabular}{|c|c|}
\hline DISCIPLINA & CONTEÚDOS / MÉTODOS \\
\hline Educação Física & $\begin{array}{l}\text { - Sua função é moralizadora, higiênica e patriótica, principalmente da ginástica; } \\
\text { - Inseparabilidade do espírito e do corpo; } \\
\text { - Música e canto; } \\
\text { - Ginástica para as meninas: movimentos calistênicos, dóceis, elegantes, sem } \\
\text { prejudicar a doçura das maneiras; } \\
\text { - Ginástica para os meninos: acrescida de exercícios militares. }\end{array}$ \\
\hline Desenho & $\begin{array}{l}\text { - finalidade prática ajustada às necessidades da indústria e da arte; } \\
\text { - Aprendizagem técnica, profissional; } \\
\text { - Método americano austríaco e inglês; } \\
\text { - Método inglês: graduação do desenho considerando: a) o desenho de memória } \\
\text { (cópias e objetos); b) o desenho de invenção (composição com elementos já } \\
\text { aprendidos); c) o desenho a tempo fixo (exercícios tirados da escala do ensino } \\
\text { imediatamente inferior à capacidade do discípulo); } \\
\text { - Método austríaco: processo estignográfico (Grandauer), aprendizagem metódica } \\
\text { das formas geométricas elementares pelo uso do papel quadriculado, sem o auxílio } \\
\text { de régua e compasso; } \\
\text { - O ensino do desenho, segundo o concebemos, deve começar na escola elementar, } \\
\text { entre as crianças de } 7 \text { anos, pelo método inglês, que se estenderá até a escola do } \\
\text { segundo grau. }\end{array}$ \\
\hline Língua materna & $\begin{array}{l}\text { - A criança deve aprender a língua falando (método intuitivo); } \\
\text { - A gramática (não tradicional) será introduzida somente a partir da } 3^{\text {a }} \text { série; }\end{array}$ \\
\hline Matemática & $\begin{array}{l}\text { - Método concreto: reconhece utilidade do cálculo mental desde que praticado sem o } \\
\text { caráter abstrato mas mediante problemas de aplicação usual, próximos da vida das } \\
\text { crianças; } \\
\text { - Para o ensino de geometria, foi indicada a adoção da taquimetria, método de ensino } \\
\text { de criado pelo engenheiro de pontes e calçadas Eduardo Lagout, que, na opinião de } \\
\text { Ruy Barbosa, significava a concretização da geometria. }\end{array}$ \\
\hline Ciências & $\begin{array}{l}\text { - A Ciência é o melhor guia para o justo desempenho das funções da família e revela } \\
\text { o sentido do progresso e da sociedade civilizada; } \\
\text { - Ruy Barbosa buscou na experiência da Inglaterra os argumentos para justificar a } \\
\text { adoção dos rudimentos das ciências físicas e naturais no programa do ensino } \\
\text { primário brasileiro; }\end{array}$ \\
\hline
\end{tabular}




\begin{tabular}{|c|c|}
\hline & $\begin{array}{l}\text { - A relevância do ensino de ciências foi ressaltada considerando sua contribuição ao } \\
\text { desenvolvimento intelectual da criança gerando hábitos de curiosidade, observação, } \\
\text { investigação e contribuição ao desenvolvimento econômico e progresso industrial; } \\
\text { - O ensino de ciências pressupunha o contato com os objetos, a observação, e a } \\
\text { experimentação, um mestre diferenciado e uso de materiais didáticos, como coleções } \\
\text { de mineralogia, botânica, zoologia, como recomendavam os pedagogos americanos. }\end{array}$ \\
\hline Geografia & $\begin{array}{l}\text { - Inicia pelas lições de lugar, pelo conhecimento do meio mais próximo - a escola, o } \\
\text { bairro, o distrito, para depois deter-se na província, no reino, nos outros países; } \\
\text { - O método consistia em partir da observação, único recurso capaz de dar } \\
\text { concreticidade aos dados e às definições; } \\
\text { - Esse mesmo procedimento aplicava-se ao ensino da cosmografia - ensino } \\
\text { elementar da astronomia - e ao ensino da cartografia, com planetários, globos } \\
\text { terrestres, cartas em relevo, cartas planas e cartas escolares parietais. }\end{array}$ \\
\hline \multirow[t]{2}{*}{ História } & - Deve começar na escola primária, com a história local, tendo a pátria como núcleo. \\
\hline & $\begin{array}{l}\text { - Os verdadeiros elementos da história não consistem no fato de referir histórias, mas } \\
\text { na aquisição de noções elementares acerca dos documentos e da maneira de apurá- } \\
\text { los; } \\
\text { - Recursos: primeiro, a investigação do aluno; depois, a palavra do mestre; por } \\
\text { último, os livros de leitura. Ênfase à narração oral dos grandes fatos da história } \\
\text { nacional feita pelo mestre de forma eloquente e o emprego do método anedótico } \\
\text { como forma de impressionar a criança e acabou se tornando popular no Brasil nas } \\
\text { séries iniciais. }\end{array}$ \\
\hline $\begin{array}{l}\text { Rudimentos de } \\
\text { economia } \\
\text { política }\end{array}$ & $\begin{array}{l}\text { - Componente curricular indispensável para a educação das classes populares e das } \\
\text { camadas operárias; } \\
\text { - A economia política, compreendendo noções sobre a riqueza, sua produção, } \\
\text { distribuição e caráter, era vista como complemento forçoso da geografia, da história, } \\
\text { das noçóes de direito social e direito pátrio. }\end{array}$ \\
\hline $\begin{array}{l}\text { Educação Moral } \\
\text { e Educação } \\
\text { Cívica }\end{array}$ & $\begin{array}{l}\text { - A Educação Moral substituiria a Educação Religiosa; } \\
\text { - Convinha desenvolver sentimentos e hábitos, cultivar valores como: respeito à } \\
\text { ordem, disciplina, abnegação, tolerância, amor ao dever, apreço ao trabalho, } \\
\text { frugalidade, o bom emprego do tempo, probidade, sinceridade, autocontrole, } \\
\text { decência, lealdade, caridade, amor à pátria; } \\
\text { - O melhor método seria o exemplo, a ação prática do mestre, o eixo, o segredo } \\
\text { irresistível de toda a educação moral; } \\
\text { - Vinculada à Educação Moral, a Educação Cívica era tida como uma de suas faces. } \\
\text { Tratava-se da educação patriótica alicerçada sobre os valores morais e intimamente } \\
\text { relacionada com a história e a geografia, }\end{array}$ \\
\hline
\end{tabular}

FONTE: Elaboração própria, a partir de Souza (2000).

Como podemos imaginar, toda essa inovação requereria da pedagogia novas posturas, novos materiais, um novo docente e, provavelmente, uma nova maneira de conceber e praticar o ensino. Neste sentido, Ruy Barbosa entendia que "todos os que se considerassem capacitados para ensinar poderiam fazê-lo, independentemente de serem professores [...] adotando os métodos que melhor lhes conviessem [...] face a ausência do Estado" (BONATO, COELHO e MENEZES, 2011, p. 279).

\section{De Ruy Barbosa a Anísio Teixeira: os objetivos da educação}


Para Ruy Barbosa, o objetivo maior da educação era modernizar a sociedade. Como esclarecem Bonato, Coelho e Menezes (2011, p. 277 - 278), autores que realizaram amplo estudo nos documentos elaborados à época, "a crença no liberalismo e no cientificismo são os pilares de sustentação para elevar o Brasil à condição de nação moderna, tendo em vista os modelos importados dos países considerados civilizados”.

Poucos anos mais tarde, no início do novo milênio, nascia Anísio Teixeira, discípulo do filósofo e pedagogo norte-americano John Dewey. Iniciou a vida pública em 1924, ocupando o cargo de diretor da Instrução Pública do Estado da Bahia. Em 1930, assumiu o posto de diretor geral da Instrução Pública do Distrito Federal, e foi nessa condição que teve a oportunidade de colocar em prática suas ideias inovadoras no âmbito da formação docente, criando o Instituto de Educação e transformando a Escola Normal em Escola de Professores (SAVIANI, 2010).

Para a sua formação pedagógica, foram decisivas as viagens que fez aos EUA, uma em 1927 e a outra em 1929, esta última para realizar o mestrado na Universidade de Columbia, estudando com seu mestre John Dewey. Essas viagens e os estudos renderam inúmeras publicações, como Aspectos Americanos da educação (1928) e Pequena introdução à filosofia da educação: a escola progressista ou a transformação da escola (reeditado em 1968) (SAVIANI, 2010). Dewey pregava a filosofia do instrumentalismo, na qual diferencia o conceito de experiência que o empirismo clássico prega. "A experiência dos empiristas clássicos é simplificada, ordenada e purificada de todos os elementos de desordem e erro, reduzida a estados de consciência caros e distintos" (REALE, 2006, p. 96).

A natureza, vista como um padrão sob cujos ditames devemos viver, tem seu ponto fraco no natural ou normal, que se confunde facilmente com o físico. $\mathrm{O}$ autor recorre a Rousseau para explicar a falsidade e a verdade dessa doutrina e este diz que recebemos a educação de três fontes: da natureza, dos homens e das coisas: "O desenvolvimento espontâneo de nossos órgãos e aptidões constitui a educação da natureza [...]. Somente quando estas três espécies de educação se harmonizam e se orientam para o mesmo fim é que um homem se dirige para seu verdadeiro destino" (DEWEY, 1959, p 124).

A teoria da harmonia educativa com a natureza foi robustecida pelo desenvolvimento da biologia, da fisiologia e da psicologia. Dewey (1959) explica a eficiência social como objetivo da educação, tendo esta como função "fornecer precisamente aquilo que a natureza deixa de proporcionar, isto é, fazer o indivíduo 
habituar-se à influência social e subordinar as faculdades inatas às regras sociais" (p. 129). Para descrever este objetivo, o autor cita a influência da economia nas decisões do educando quanto à sua carreira profissional, e a importância da eficiência cívica no que diz respeito às habilidades inatas do ser humano e à qualidade de um bom cidadão. Além disso, coloca a cultura como objetivo da educação, sendo algo pessoal o cultivo da apreciação de ideias. O autor enfatiza que a eficiência social, como finalidade educativa, deve significar a participação livre e plena de atividades comuns, e isso é impossível sem cultura. Essa eficiência social pode ser atualmente vista quando Políticas Públicas Educacionais são criadas a fim de que se ofereça uma educação de qualidade, estando a escola à disposição do aluno em tempo integral. Entretanto, para implantar essa política leva-se tempo e condições estruturais e humanas a fim de que se possa atender toda a demanda de alunos do nosso país.

\section{A educação integral de tempo integral}

Voltando Ao Brasil Imperial, mais uma vez vamos recorrer aos fatos históricos para entender melhor as entrelinhas: levando em conta a lei do Ventre Livre de 1871, constatamos, com Bonato, Coelho e Menezes (2011), que em 1879 as crianças nascidas livres, filhas de escravas, completariam oito anos. Este fato geraria um problema ao Estado Imperial: onde alocar esta população livre, num país que queria ser considerado moderno e civilizado? Como o governo não tinha (nem pretendia ter) uma estrutura que pudesse acolhê-las, as propostas de instrução e de constituição de associações em parceria com particulares para oferecer educação de tempo integral eram bem vistas (FONSECA, 2002).

Como vimos, as políticas públicas educacionais normalmente revestem-se de uma intencionalidade ideológica, e com a primeira proposta de educação de tempo integral não foi diferente. Desta forma, a proposta de Leôncio de Carvalho ampliava a jornada escolar para "seis horas diárias para jovens com dez anos ou mais" (BONATO, COELHO e MENEZES, 2011, p. 280). Além disso, segundo averiguaram os autores, a educação de tempo integral da época contava com bibliotecas e museus escolares, mostrando uma preocupação com os espaços e não somente com o tempo em que as crianças deveriam permanecer na escola. 
Neste sentido, o visionário Ruy Barbosa fez uma distinção entre educação/ensino integral e tempo integral na escola. Com relação a este último, Bonato, Coelho e Menezes (2011, p. 286) esclarecem que ele enfatizava que "a questão não está presente na extensão do horário escolar mas sim na importância de que, a cada aula, haja um intervalo que recompense o esforço desprendido pela criança”. Em outras palavras: a integralidade atribuída ao ensino não estaria relacionada com o tempo, mas com "a égide da mesma trindade pedagógica defendida pelos médicos higienistas: educação física, intelectual e moral" (BONATO, COELHO e MENEZES, 2011, p. 281). Já na época, Ruy Barbosa dedicou dezenas de laudas a criticar a pedagogia da memorização e da repetição, o que nos anos de 1970 Paulo Freire chamaria de pedagogia bancária ${ }^{6}$. Seguindo o método intuitivo, a lição de coisas, a educação integral representava para Ruy Barbosa a indissociabilidade entre corpo e espírito. Ainda sobre o método integral, o próprio ministro do Império, Leôncio de Carvalho, dizia que "o ensino deveria fornecer ao menino a capacidade de ver, de sentir, de esquadrinhar, executar, de inventar" (BONATO, COELHO e MENEZES, 2011, p. 286).

Como podemos perceber, quanto mais nos debruçamos sobre os fatos e feitos históricos em seus detalhes, as identificações não param de surpreender-nos. Além da proximidade das críticas que Ruy Barbosa tecia à pedagogia da memorização e da repetição com a pedagogia bancária criticada por Paulo Freire, as recomendações de Leôncio de Carvalho e Ruy Barbosa (ainda no Brasil Imperial!) sobre os métodos de ensino baseados na experiência, aproximam-se sobremaneira da experimentação de Dewey e Anísio Teixeira!! (Os quais recorreram a Rousseau, com seu Emílio!!). Apesar de não ser este o objetivo deste trabalho, poderíamos inclusive ir mais longe: considerando que Barbosa e Carvalho se baseavam na Lei do desenvolvimento orgânico de Herbert Spencer (1820 - 1903), especialmente na obra Educação intellectual, moral e physica (1861), é possível ver uma forte aproximação e influência das ideias de desenvolvimento orgânico ${ }^{7}$ deste autor na teoria de escola unitária do italiano Antônio Gramsci (1981 - 1937).

O curioso é que a educação/ensino integral, seja no sentido de sua integralidade enquanto aos seus fins como referíamos, seja com relação ao tempo integral, proposta

${ }^{6}$ FREIRE, Paulo. Pedagogia do oprimido. $17^{\mathrm{a}}$ edição. Rio de Janeiro: Paz e Terra, 1987.

7 "A escola unitária deveria ser organizada como escola em tempo integral, com vida coletiva diurna e noturna, liberta das atuais formas de disciplina hipócrita e mecânica, e o estudo deveria ser feito coletivamente, com a assistência dos professores e dos melhores alunos, mesmo nas horas do estudo dito individual, etc." (GRAMSCI, 2001, p. 38). 
pelos autores citados no parágrafo anterior - ainda que guardadas algumas proporções -, basicamente com um método baseado na experimentação e contrário ao trabalho mecânico e escravizado (GRAMSCI, 2001), vem sido debatida há cerca de 300 anos, mas, na prática, pouco avançamos. Nóvoa (2014) diz que sabemos o que deve ser feito, mas não o fazemos. $\mathrm{O}$ autor completa, referindo que temos docentes do século $\mathrm{XX}$, trabalhando com estudantes do século XXI e aplicando métodos do século XIX (embora que, se levarmos em conta métodos do século XIX como os aqui descritos, estamos defasados inclusive com relação a eles!).

No Brasil, é a partir dos últimos anos que se vê, por meio do Programa Mais Educação, uma maior preocupação como a implantação de ações desse tipo (PARENTE, 2014). O Plano Nacional de Educação (PNE), Lei n. 13.005, de 25 de junho de 2014, estabelece a meta $n^{\circ}$ 06, que é “oferecer educação em tempo integral em, no mínimo, 50\% (cinquenta por cento) das escolas públicas, de forma a atender, pelo menos, 25\% (vinte e cinco por cento) dos(as) alunos(as) da educação básica" (BRASIL, 2010). Como estratégias para esta meta, o Plano, prevê, principalmente:

6.1) Atividades de acompanhamento pedagógico e multidisciplinares, inclusive culturais e esportivas, de forma que o tempo de permanência dos (as) alunos (as) na escola, ou sob sua responsabilidade, passe a ser igual ou superior a 7 (sete) horas diárias durante todo o ano letivo, com a ampliação progressiva da jornada de professores em uma única escola; 6.2) [...] construção de escolas com padrão arquitetônico e de mobiliário adequado para atendimento em tempo integral; 6.3) [...] instalação de quadras poliesportivas, laboratórios, inclusive de informática, espaços para atividades culturais, bibliotecas, auditórios, cozinhas, refeitórios, banheiros e outros equipamentos, bem como da produção de material didático e da formação de recursos humanos para a educação em tempo integral; 6.4) fomentar a articulação da escola com os diferentes espaços educativos, culturais e esportivos e com equipamentos públicos, como centros comunitários, bibliotecas, praças, parques, museus, teatros, cinemas e planetários; 6.5) estimular a oferta de atividades voltadas à ampliação da jornada escolar de alunos (as) matriculados nas escolas da rede pública de educação básica por parte das entidades privadas de serviço social vinculadas ao sistema sindical, de forma concomitante e em articulação com a rede pública de ensino; [...] 6.9) adotar medidas para otimizar o tempo de permanência dos alunos na escola, direcionando a expansão da jornada para o efetivo trabalho escolar, combinado com atividades recreativas, esportivas e culturais.

Podemos notar que a meta é ousada, e suas estratégias igualmente. Desta maneira, o Programa Mais Educação, ao qual nos dedicamos mais especificamente na sequência, tornou-se uma das principais ferramentas para o seu cumprimento. A 
ampliação da jornada, portanto, pautou-se em atividades optativas nos macrocampos: “acompanhamento pedagógico; educação ambiental; esporte e lazer; direitos humanos em educação; cultura e artes; cultura digital; promoção da saúde; comunicação e uso de mídias; investigação no campo das ciências da natureza e educação econômica" (MEC, 2010). Segundo o projeto pedagógico pelo qual a escola optou, esta escolhe seis atividades, anualmente. A questão é que, devido às últimas medidas de ajuste fiscal tomadas pelo governo Federal, houve uma grande redução de verbas, inclusive do Mais Educação, comprometendo seriamente o cumprimento da meta 06 do PNE.

É notória a influência de Anísio Teixeira nos materiais de apoio que o Ministério da Educação disponibiliza para a implantação de Programas como o Mais Educação. Esse fato se deve, entre outros, à exitosa experiência da Escola Parque, instalada em Brasília no mesmo ano de inauguração da cidade, uma instituição de educação integral que, "sob a influência das ideias pragmatistas de Dewey, [...] é concebida com funções bem mais amplas do que as da escola tradicional e se organiza como uma comunidade socialmente integrada, de modo a se constituir numa real experiência de vida"(PEREIRA e ROCHA, 2006, p. 5002).

\section{Escola Parque, Mais Educação e a (des)continuidade}

Como referimos, a Escola Parque foi criada por Anísio Teixeira em 1960, quando este era diretor do Instituto Nacional de Estudos e Pesquisas Educacionais (hoje denominado Instituto Nacional de Estudos e Pesquisas Educacionais Anísio Teixeira INEP). Segundo Pereira e Rocha (2006), a escola seguiu o modelo de outra criada por Anísio Teixeira em 1950, o Centro Carneiro Ribeiro, em Salvador, quando ele foi Secretário da Educação, conhecida também como Escola Parque da Bahia. Os autores ressaltam o valor simbólico de uma escola como essa na nova capital do país, cuja função era a de constituir-se em um exemplo para o sistema educacional brasileiro. Comparada com uma universidade infantil (TEIXEIRA, 1961), como costumava dizer Anísio Teixeira, a Escola Parque atendia a aproximadamente dois mil alunos em dois turnos. As atividades eram de

Iniciação para o trabalho (para alunos de 7 a 14 anos), nas pequenas "oficinas de artes industriais" (tecelagem, tapeçaria, encadernação, cerâmica, cartonagem, costura, bordado e trabalhos em couro, lã, 
madeira, metal, etc.), além da participação dirigida dos alunos de 7 a 14 anos em atividades artísticas, sociais e de recreação (música, dança, teatro, pintura, exposições, grêmios, educação física) (PEREIRA e ROCHA, 2006, p. 5005).

Assim, criticando a escola tradicional, de caráter propedêutico, intelectualista e seletiva, Anísio Teixeira propôs um programa abrangente, integral: quatro horas de educação intelectual e quatro horas na Escola Parque. Segundo o próprio idealizador, dessa maneira há uma associação entre a educação elementar com o ensino "propriamente intencional, da sala de aula, com a autoeducação resultante de atividades de que os alunos participem com plena responsabilidade. Por isto, o horário escolar se estende por oito horas, divididas entre as atividades de estudo e as de trabalho, de arte e de convivência social" (Teixeira, 1961, p.197).

Além disso, Pereira e Rocha (2006) destacam que existia um planejamento integrado entre a Escola Parque e a Escola Classe, de maneira a alcançar um desenvolvimento integral do aluno e do próprio professor, posto que "se os professores deveriam proporcionar aos alunos experiências que os levassem a desenvolver hábitos de responsável auto direção e de cooperação social, eles mesmos tinham que trabalhar dentro de uma linha participativa e cooperativa" (MOREIRA, 2002, p. 102). No decorrer de dois anos, porém, começaram a aparecer as dificuldades de cunho orçamentário: das 28 escolas previstas, foram efetivamente construídas cinco; houve redução das horas de permanência dos alunos de quatro para duas, bem como dos professores; nos anos posteriores, com a falta de escola e o aumento da demanda, a expansão de matrículas foi tão grande que os alunos passaram a frequentar a Escola Parque em dias alternados, desfigurando completamente a proposta original.

Hoje a história se repete: segundo o Centro de Referências em Educação Integral, os recursos do Mais Educação, que chegaram a alcançar quase 60 mil escolas em 2015, foram reduzidos a 26 mil escolas em 2016 (ZINET, 2016). O Programa Mais Educação, criado pela portaria 17/2007, regulamentado pelo decreto 7.083/10, surgiu como uma estratégia do Ministério da Educação para induzir a construção da agenda de educação de tempo integral nas redes públicas, ampliando a jornada escolar para no mínimo sete horas diárias.

Atendendo inicialmente às escolas com baixo Índice de Desenvolvimento da Educação Básica (IDEB), aos poucos foi fazendo a adesão por meio de formulário eletrônico. O Mais Educação “tem por objetivo fomentar a Educação Integral de crianças, adolescentes e jovens, por meio de atividades socioeducativas, no contraturno 
escolar, articuladas ao projeto de ensino desenvolvido pela escola" (MEC, 2009, p 24). Importante ressaltar, conforme texto referência para debate nacional, que esse Programa conta com a participação de ações promovidas pelos Estados, Distrito Federal, Municípios e por outras instituições públicas e privadas. Além do mais, a articulação entre Educação, Assistência Social, Cultura e Esporte, dentre outras políticas públicas, poderá se constituir como intervenção para a proteção social, prevenção a situações de violação de direitos da criança e do adolescente, e, para melhoria do desempenho escolar e da permanência do aluno na escola, principalmente em territórios mais vulneráveis.

Conforme o $\operatorname{artigo} 3^{\circ}$ do Decreto 7.083/10, são objetivos do Programa Mais Educação:

I- formular política nacional de educação básica em tempo integral; II - promover diálogo entre os conteúdos escolares e os saberes locais; III - favorecer a convivência entre professores, alunos e suas comunidades; IV-disseminar as experiências das escolas que desenvolvem atividades de educação integral; e V-convergir políticas e programas de saúde, cultura, esporte, direitos humanos, educação ambiental, divulgação científica, enfrentamento da violência contra crianças e adolescentes, integração entre escola e comunidade, para o desenvolvimento do projeto político-pedagógico de educação integral (BRASIL, 2010, p. 1).

O programa é operacionalizado pela Secretaria de Educação Básica (SEB) por meio do Programa Dinheiro Direto na Escola (PDDE), do Fundo Nacional de Desenvolvimento da Educação (FNDE). São oferecidas para as escolas diferentes áreas para emprego das atividades a serem realizadas no contraturno escolar, assim, para ampliação do cenário educativo e, portanto, das oportunidades formativas oferecidas pelas escolas,

As atividades fomentadas foram organizadas nos seguintes macrocampos: acompanhamento pedagógico, educação ambiental, esporte e lazer, direitos humanos em educação, cultura e artes, cultura digital, promoção da saúde, comunicação e uso de mídias, investigação no campo das ciências da natureza e educação econômica (MEC, 2015, p 8).

De acordo com essa proposta, a escola deve escolher seis atividades a cada ano dentro do universo das possibilidades (os 10 macrocampos) destacadas anteriormente, sendo que uma delas obrigatoriamente deve compor o macrocampo Acompanhamento Pedagógico. Para cada macrocampo, são oportunizadas diversas atividades que podem ser desenvolvidas na escola através de oficinas. No macrocampo Acompanhamento Pedagógico, as oficinas que podem ser trabalhadas são: Ciências, Filosofia e Sociologia, 
História e Geografia, Letramento, Línguas estrangeiras, Matemática e Tecnologias de Apoio a Alfabetização. Já no Macrocampo Educação Ambiental têm-se as oficinas de Educação para a Sustentabilidade e Horta escolar e/ou comunitária. O Esporte e Lazer compreendem as atividades voltadas para: Atletismo, Basquete, Basquete de rua, Ciclismo, Corrida de orientação, Futebol, Futsal, Ginástica rítmica, Handebol, Ioga, Judô, Karatê, Natação, Programa Segundo Tempo (ME), Recreação/lazer, Taekwondo, Tênis de campo, Tênis de mesa, Voleibol, Xadrez tradicional, Xadrez virtual (MEC, 2015).

No Macrocampo dos Direitos Humanos e Educação, as oficinas devem trabalhar com o conhecimento sobre os direitos humanos e vivências dos mesmos pelos educandos. Na Cultura e Artes as oficinas que podem ser oferecidas nas escolas são: Banda fanfarra, Canto coral, Capoeira, Cineclube, Danças, Desenho, Escultura, Flauta doce, Grafite, Hip hop, Leitura, Mosaico, Percussão, Pintura, Prática circense, Teatro, Instrumentos de Corda. E o Macrocampo Cultura Digital deve oportunizar aos alunos o aprendizado em Software educacional/Linux Educacional, domínio da informática e tecnologia da informação (Proinfo e/ou laboratório de informática) e ambiente de redes sociais.

No macrocampo Promoção da Saúde devem ser desenvolvidas:

Atividades de alimentação saudável/alimentação escolar saudável,
saúde bucal, atividades físicas e corporais; garantia dos direitos
sexuais e reprodutivos; prevenção ao uso de álcool, fumo e outras
drogas; saúde ambiental; promoção da cultura de paz e prevenção em
saúde a partir da análise situacional das condições de saúde do escolar
(dengue, febre amarela, malária, hanseníase, doença falciforme, H1N1
e outras). Propõe-se neste macrocampo o fortalecimento e a ampliação
da estratégia de protagonismo juvenil desenvolvida pelo Projeto Saúde
e Prevenção na Escola - SPE que integra o Programa Saúde na Escola
(PSE). (MEC, 2015, p 12)

Na Comunicação e uso de mídias, os alunos poderão estar realizando atividades através da implantação de um jornal escolar, vivências com rádio escolar, construção de histórias em quadrinhos, fotografia e vídeo (MEC, 2015). Na Iniciação à Investigação das Ciências da Natureza são oferecidos aos alunos conhecimentos por meio de atividades feitas em Laboratório, feiras de ciências e projetos científicos, podendo se estender até o campo da robótica. E por fim, no macrocampo da Educação Econômica os alunos aprenderão noções sobre educação econômica e educação fiscal e financeira (MEC, 2015). 
Pode-se observar a amplitude de conhecimentos e aprendizagens que as oficinas pertencentes aos macrocampos podem oferecer aos alunos, entretanto, a participação é voluntária, ou seja, o aluno matriculado na escola pode optar por não aderir ao projeto. Considera-se a realidade de cada escola que, de acordo com a disponibilidade de espaço físico, pode definir quantos alunos serão atendidos, privilegiando aqueles que estão em vulnerabilidade. A proposta do Programa Mais Educação vai ao encontro da Educação de Tempo Integral. O material encontrado nos documentos legais, disponíveis no site do Ministério da Educação, são enfáticos no que diz respeito à implantação do Programa, corroborando com a proposta da Educação de Tempo integral para o território brasileiro. Ainda assim, a exemplo do que aconteceu em 1962 com Anísio Teixeira, mais uma vez, quando o país passa por problemas econômicos, os cortes são sentidos na carne sempre pela área da educação, por razões ideológicas e financeiras, dificultando a continuidade destes programas.

\section{Palavras finais}

Pensar em uma educação de tempo integral que tenha objetivos relevantes é pensar em atitudes que promovam o desenvolvimento do ser humano em sua plenitude. O tempo em que o aluno está na escola deve ser proveitoso e promover um aprendizado eficaz nas mais diversas áreas do conhecimento humano.

O PNE (2014-2024) e o Programa Mais Educação surgem como forma de guiar os rumos da educação no país, oferecer subsídio para a atuação dos professores, das instituições e dos governantes, para estabelecer regras e ditames responsabilizando diferentes segmentos da sociedade para a melhoria da educação brasileira. Esses mecanismos surgem também a fim de propiciar aos cidadãos uma formação de qualidade que contemple todos os segmentos da sociedade, de maneira democrática. Com objetivo de eficiência social e cultura pessoal do indivíduo, a educação deve rumar para esses propósitos, sendo de fundamental importância o meio em que o aluno está inserido e a sua cultura. A escolha das oficinas a serem trabalhadas no programa Mais Educação dentro das escolas fica a critério do estabelecimento, que em conjunto com o Projeto Político Pedagógico da escola buscam o desenvolvimento integral do educando.

A questão é que, mais uma vez, uma proposta de Educação de Tempo Integral no Brasil tem seu desenvolvimento ameaçado pelos cortes de recursos econômicos e 
pela política da descontinuidade. Concordando com as proposições de Anísio Teixeira, temos um longo caminho a ser percorrido para que se efetive uma educação que atenda às necessidades da população no que diz respeito à eficiência social. Pensar uma educação neste sentido requer muito planejamento entre os agentes envolvidos no processo, seja professores ou representantes do governo. Com relação à Educação de Tempo Integral, temos o suporte legal (que é o PNE 2014-2024 e o Programa Mais Educação) e, pese a que não tenhamos todos os recursos físicos, estruturais e humanos necessários, se caminhava avançando, o que agora se interrompe. É mister, portanto, o estabelecimento de mecanismos de resistência que possibilitem a efetivação das metas já traçadas e dos programas já instituídos, bem como esforços de todas as esferas envolvidas - comunidade escolar em geral -, de maneira a impedir que o retrocesso, o descaso, o desconhecimento, e a falta de prioridade da educação nas políticas públicas continuem com este ciclo vicioso.

\section{Referências}

BONATO, N. M. C; COELHO, M. C. C; MENEZES, J. S. S. Educação Integral, ensino integral e tempo no pensamento de Rui Barbosa. Revista HISTEDBR On-line, Campinas, n. 44, p. 275-292, dez. 2011.

BRASIL. Decreto no 7.083 de 27 de Janeiro de 2010. Dispõe sobre o Programa Mais Educação. Disponível em: < https://www.planalto.gov.br/ccivil_03/_ato20072010/2010/decreto/d7083.htm>. Acesso em: 14 abr. 2015.

Plano Nacional de Educação 2014-2024. Lei no 13.005, de 25 de junho de 2014. Disponível em < http://www.planalto.gov.br/ccivil_03/_ato20112014/2014/lei/113005.htm>. Acesso em: 06 de abr. 2016.

CARNEIRO, Moaci Alves. O Nó do Ensino Médio. Petrópolis, RJ: Vozes, 2012.

DEWEY, John. Democracia e Educação: Introdução à filosofia da Educação. Traduzido por Anísio Teixeira e Godofredo Rangel. São Paulo: Companhia Editora Nacional, 1959.

FERREIRA, Aurélio Buarque de Holanda. Dicionário Aurélio Básico da Língua Portuguesa. Rio de Janeiro: Nova Fronteira, 2010.

FONSECA, Marcus Vinícius. A educação dos negros: uma nova face do processo de abolição da escravidão no Brasil. Bragança Paulista: EDUSF, 2002. 
GRAMSCI, A. Caderno do Cárcere, Volume 2; edição e tradução Carlos Nelson Coutinho; coedição Luiz Sérgio Henriques e Marco Aurélio Nogueira - $2^{a}$ edição. Rio de Janeiro: Civilização Brasileira, 2001.

KOSIK, Karel. Dialética do Concreto. Tradução de Célia Neves e Alderico Toríbio. $2^{\mathrm{a}}$ ed. Rio de Janeiro: Paz e Terra, 1976.

MEC. Ministério da Educação. Programa Mais Educação. 2010. Disponível em: $<$ http://portal.mec.gov.br/index.php?option=com_content\&id=16689\&Itemid=1115>. Acesso em: 14 abr. 2015.

MEC. Educação integral: texto referência para o debate nacional. Brasília: MEC, SECAD, 2009.

MOREIRA, Carlos Otávio Fiúza. Entre o indivíduo e a sociedade: um estudo da filosofia da educação de John Dewey. Bragança Paulista: EDUSF, 2002.

NÓVOA, António. Transnacionalização das Políticas Educacionais: Impactos na formação docente - Conferência proferida no VIII Simpósio Nacional de Educação e II Colóquio Internacional de Políticas Educacionais e Formação de Professores. Revista de Ciências Humanas - Educação. v. 16, n. 27, p. 160-179, Dez. 2015.

PARENTE, C. M. D. Educação em Tempo Integral e Programa Mais Educação: aproximações e distanciamentos das regiões brasileiras em relação à meta prevista no projeto de lei do novo Plano Nacional de Educação (PNE). Revista Contrapontos Eletrônica, Vol. 14 - n. 3 - set-dez 2014.

PEREIRA, Eva W.; ROCHA, Lúcia Maria Franca. Escola Parque de Brasília: uma experiência de educação integral. In: VI Congresso Luso-Brasileiro de História da Educação, 2006, Uberlândia. Percursos e Desafios da Pesquisa e do Ensino da História da Educação, 2006.

PETITAT, A. A produção da escola, produção da sociedade: Análise sócio-histórica de alguns momentos decisivos da evolução escolar no Ocidente. Porto Alegre: Artes Médicas, 1994.

REALE, G. História da Filosofia. São Paulo: Paulus, 2006.

SAVIANI, Dermeval. História das ideias pedagógicas no Brasil. Campinas, SP: Autores Associados, 2010.

SOUZA, R. F. Inovação educacional no século XIX: A construção do currículo da escola primária no Brasil. Cadernos Cedes, ano XX, no 51, novembro/2000.

TEIXEIRA, Anísio. Plano de Construções Escolares de Brasília. Revista Brasileira de Estudos Pedagógicos. Rio de Janeiro, 35 (81): 195:199, jan./mar. 1961.

ZINET, Caio. MEC reformula Mais Educação e reduz seu alcance a 26 mil escolas. Notícia - 22/03/2016. Portal do Centro de Referências em Educação Integral. 
Disponível em: <http://educacaointegral.org.br/noticias/mec-reformula-mais-educacaoreduz-alcance-26-mil-escolas/>. Acesso em: 06 ago. 2016.

ZOTTI, Solange Aparecida. "Currículo". In: HISTEDBR, Grupo de Estudos e Pesquisas História, Sociedade e Educação no Brasil - 20 anos. Navegando na história da Educação Brasileira - Glossário. Faculdade de Educação, Unicamp, 2006.

Disponível em: <http://www.histedbr.fe.unicamp.br/navegando/a.html>. Acesso em: 04 ago. 2016.

\section{Como referenciar este artigo}

SCHEUERMANN, Aniele Elis; JUNG, Hildegard Susana; CANAN, Silvia Regina. Educação de tempo integral no Brasil, passos e descompassos: de Ruy Barbosa e Anísio Teixeira aos dias atuais. Revista Ibero-Americana de Estudos em Educação, Araraquara/SP, v.12, n.1, p. 422-439, 2017. Disponível em: <http://dx.doi.org/10.21723/riaee.v12.n1.8911>. E-ISSN: 1982-5587.

Submetido em: set/2016

Aprovação final em: fev/2016 